\title{
TEOLOGI TAHAJJUD \\ PEMIKIRAN PROF. DR. MOH. SHOLEH MELAWAN METOS SANGKAL DI KALANGAN MASYARAKAT KABUPATEN SUMENEP MADURA
}

\author{
Zaitur Rahem \\ Institut Ilmu Keislaman Annuqayah Guluk-Guluk Sumenep Madura \\ Emai: zaitur_rahem@yahoo.co.id
}

\begin{abstract}
The community formed by the trappings of culture. The birth of a sense of cultural initiative, creativity, and initiative of human social life. Each community in various regions has its own culture. All of theIT formed over social accumulation, Bohemian flavor, and the results kesepakata together. Depth on creating, meruwat, and caring culture in Indonesian society is very strong. On the island of Madura, a sense of belonging to that culture is still strong. Including culture believing in things that are myths. This study will reveal the myths deny reality in the Madurese community. With qualitatively method, researchers will collect data from a number of sources. Data collection will be done with the snowball sampling technique. All information obtained from informants become authoritative data in terms of writing this review. of the research, found that refute the myth has no empirical basis. Deny only be born of anxiety Madurese community. Solutions address the threat to deny the myth is Denen taqarruban ilallah through prayer tahajud media. Salah tahajud alternative enjadi soothe the soul and maintain the stability of functioning organs become more finally.

Keyword: Teologi, Tahajud, Metos, Sangkal
\end{abstract}

\section{Pendahuluan}

Mencari jodoh itu gampang-gampang sulit. Sebab, sejumlah orang terkadang mencari jodoh merasa sulitnya minta ampun. Wajar jika pada beberapa bulan lalu, salah satu kelompok musik terkemuka Wali meramu lagu yang diantara liriknya, 'tak laku-laku'. Kemungkinan besar, lagu tersebut hendak dijadikan representasi sejumlah orang yang frustasi memikirkan jodoh atau pasangannya harus dicari kemana. Istilah 'tak laku-laku' dalam kamus bahasa Madura sering disebut dengan sangkal. Dalam ajaran teologis, jodoh adalah wilayah kewenangan Tuhan. Namun, pada prinsip humanitas, kewenangan Tuhan

Palapa: Jurnal Studi Keislaman dan Ilmu Pendidikan

Volume 5, Nomor 1, Mei 2017; p-ISSN 2338-2325; e-ISSN 2540-9697; 1-13 
tidak seharusnya ditafsir secara ekslusif. Tuhan memang pemegang mutlak kewenangan. Akan tetapi, Tuhan memberikan peluang besar kepada manusia untuk mengetuk kewenangan Tuhan seperti apa yang diharapkan manusia. Manusia bebas berdoa akan tetapi Tuhan yang memiliki kehendak. Jodoh sudah ditentukan sejak azal, namun usaha mengejar jodohnya tugas manusia di bumi.

Jodoh harus dicari! Bagaimana memulai pencarian jodoh? Ibarat orang melakukan petualangan, jodoh juga harus ada ikhtiyar menemukannya. Travelling of jodoh. Petualangan mencari jodoh itu sangat dianjurkan oleh agama. Dalam sebuah hadis Nabi Muhammad SAW digariskan, apabila seseorang berkehendak mempersunting (menikah) seorang perempuan hendaknya dia memerhatikan keluarga, harta, kecantikan, dan agamanya. Apabila dari sekian indikator yang disyariatkan tidak ditemukan, cukuplah agama sebagai pilihan terakhir. ${ }^{1}$ Ketentuan tersebut diperkuat dengan ajaran Al-Quran, Tuhan tidak akan mengubah keadaan suatu komunitas (umat) kecuali mereka melakukan perubahan dengan potensi dan produktivitas yang ada dan dilakukan sendiri. Kedua perspektif teologis itu tentu memiliki efek multidisiplin dengan sudut kajian multimetodologis. Termasuk, memulai pencarian jodoh dengan usaha maksimal dari tiap orang.

Ada banyak cara untuk menemukan jodoh yang diidamkan., langkah efektif untuk menemukan jodoh dengan mendekatkan diri kepada Tuhan. Metode yang dipergunakan adalah intensif melaksanakan shalat tahajjud. Shalat tahajjud sendiri merupakan ibadah sunnah dengan sekian kesitimewaan. Status sunnah dalam literatur syariah Islam adalah pekerjaan yang apabila dikerjakan akan mendapat pahala. Namun, jika tidak dilaksanakan juga tidak mendapat sanksi teologis. Shalat tahajjud, dalam praktiknya dilaksanakan pada malam hari. Yaitu, pada separuh malam (nisfu al-lai). Adapun hitungan rakaat shalat sunnah, ulama fikih berbeda-beda pendapat. Sedangkan keutamaan melaksanakan shalat malam banyak dijelaskan dalam literatur ilmu syariah. Bahkan, dalam al-Quran ditegaskan, shalat malam adalah shalat yang segala doa akan dikabulkan oleh yang Maha Kuasa. Keistimewaan shalat malam (tahajjud) berbeda

\footnotetext{
${ }^{1}$ Pauline Leander, We Love Stress, (Jakarta: Gramedia Pustaka Utama, 2013), 23.
} 
dengan shalat sunnah lainnya. Sehingga, melaksanakan shalat tahajjud dianggap efektif dan cara paling jitu untuk mendapatkan do'i idaman. Namun dengan catatan, shalat tahajjud yang dilakukan didasari dengan niat yang tulus dan kuat. Niat yang kuat dan tulus akan menjadikan ibadah yang dilakukan lebih masimal. InsyaAllah, dengan kekuatan doa yang disiplin tersebut, jodoh yang selalu kita minta kepada Tuhan akan segera didapatkan. Bagaimana jika tidak didapatkan? Dalam ajaran ilmu-ilmu tasawuf, bentuk pemberian dari Tuhan itu ada dua macam. Yaitu, pemberian yang diberikan ketika manusia itu hidup di dunia. Yang kedua, pemberian yang diberikan Tuhan di saat manusia itu sudah berada di alam akhirat kelak. Semua yang kita minta pada prinsipnya akan dikabulkan oleh Tuhan. ${ }^{2}$

Sisi keunikan buku ini, selain mengulas keutamaan tahajjud juga diselipkan sejumlah cerita tentang hikmah melaksanakan ibadah sunnah tahajjud ini. Mulai dari cerita seseorang yang ingin mendapatkan harta berlimpah dan persoalan jodoh. Tahajjud sebenarnya bukan sebatas ibadah sunnah yang kepentingan untuk mengabdi kepada Tuhan saja. Akan tetapi, jauh dari sisi ibadah tersebut, melaksanakan shalat tahajjud adalah media untuk mensucikan diri dari segala belenggu dunia yang semakin kusut. Seperti ulasan buku ini, pada separuh malam seseorang akan menemukan puncak ketenangan alam raya. Ibarat jalan transportasi, maka jalan tol merupakan jalan alternatif di saat jalan raya umum macet. Jalan tol menjadi ruang bebas bagi sejumlah kendaraan agar lajunya lebih lancar. Shalat tahajjud adalah shalat penuh makna jika dikerjakan dengan sungguh-sungguh dan penuh ketulusan. Mampukah shalat tahajjud sebagai terapi metafisik menyelesaikan berbagai masalah kehidupan? Bagaimana potensi shalat tahajjud dalam pandangan medis dan sains?

\section{Sketsa Singkat Prof. Dr. Moh. Sholeh}

Prof. Dr. Moh. Sholeh lahir di Kediri pada tanggal 09 Desember 1960. Beliau termasuk Pemuda cakap dan multitalenta. Sejak usia muda beliau memiliki komitmen luar biasa untuk mencari dan mewujudkan mimpi-mimpinya. Karir pendidikannya, tahun 1993 pernah menjabat sebagai kepala madrasah Aliyah (MA) Caruban. Pengabdian di

\footnotetext{
${ }^{2}$ Ibnu 'Athaillah, Al-Hikam, (Jakarta: Zaman, 2015), 50.
} 
dunia pendidikan merupakan bakti tak ternilai bagi Prof. Dr. Moh. Sholeh. Pengetahuan dan pengalaman akademik yang dia miliki dia aktualisasikan dalam praktik di lembaga pendidikan. Setelah lepas sebagai kepala MA Caruban, tahun 1996 hingga saat ini mengabdi sebagai dosen di fakultas tarbiyah IAIN Sunan Ampel Surabaya. Sebelum masuk ke ranah institusi struktural, Prof. Dr. Moh. Sholeh menempuh jenjang pendidikan strata satunya (S1) di fakultas tarbiyah Universita Muhammadiyah Malang, tahun 1987. Lalu pada tahun 1993, beliau menyelesaikan program master pendidikan di fakultas phisikologi Konseling IKIP Negeri Malang. Pada tahun 2000 meraih gelar doktor di Fakultas kedokteran Universitas Air Langga Surabaya pada jurusan Imunologi. Puncak karir pendidikan beliau pada tahun 2004, setelah mendapatkan gelar guru besar pada bidang Phisikologi Islam³

Pengetahuan Prof. Dr. Moh. Sholeh di bidang pengetahuan phisikologi dalam sudut pandang Islam patut diajungi jempol. Sebab, pendekatan kesehatan medis yang dia peroleh mampu membuka cakrawala bernalar umat Islam. Ajaran Agama Islam itu kompleks ketika dilakukan telaah dan kajian secara kompherensif, berdasarkan konteks kehidupan. Selain aktif di jagad akademik, Prof. Dr. Moh. Sholeh juga aktif berbagai kegiatan sosial keagamaan. Terbukti di tengah-tengah jeda kesibukannya mengisi kuliah di sejumlah perguruan tinggi, dia membuka praktik klinik phisikoneuroimunologi di masjid Akbar Surabaya. Praktik klinik ini secara faktual memosisikan Prof. Dr. Moh. Sholeh sebagai pribadi yang multitalenta. Pengetahuan dan pengalamannya berjalan hirarkhis dan dirasakan banyak orang. Di ranah kampus, beliau juga memberikan materi kuliah seputar kompetensi keilmuan yang ditekuni oleh Prof. Dr. Moh. Sholeh. Saat ini, beliau tercatat sebagai salah seorang akademisi yang aktif menulis pemikiran ke sejumlah media. Baik media dalam skala lokal, nasional, dan internasional.

Adapun sejumlah karya ilmiah Prof. Dr. Moh. Sholeh diantaranya, Pertama, Terapi Shalat tahajjud; Menyembuhkan Berbagai Penyakit. Kedua, Telaah Nilai Ajaran Al-Ghazali sebagai Suatu Alternatif Pendekatan Psikologi. Ketiga, Korelasi Antara Keseringan Puasa Senin-Kamis dengan Penurunan Kecemasan. Keempat, Pengaruh

\footnotetext{
${ }^{3}$ Moh. Sholeh, Terapi Shalat Tahajud, (Jakarta: Noura Books, 2016), 233
} 
Permainan Ganda terhadap Peningkatan Kreativitas Anak. Kelima, Korelasi Antara Keseringan Shalat Sunah terhadap Penurunan Kecemasan. Kelima, Korelasi Antara Keseringan Membaca Al-Quran dengan Penurunan Kecemasan². Karya-karya Prof. Dr. Moh. Sholeh termasuk karya ilmiah dengan sudut pandang keislaman.

\section{Pulau Madura sebagai Magnet Kajian ilmu Pengetahuan}

Pulau Madura merupakan bagian dari Indonesia. Dalam kuasa demografis, madura menjadi wilayah kewenangan pemerintah propinsi Jawa Timur. Di pulau ini terdapat empat kabupaten, yaitu kabupaten Bangkalan (ujung Barat), Sampang, Pamekasan, dan Sumenep (ujung timur). Setiap kabupaten memiliki kecamatan dan desa sebagai bagian integeral dari kekuasaannya. Dalam kajian ini, lokasi penelitian kabupaten Sumenep. Kabupaten Sumenep merupakan bagian kawasan di pulau Madura. Sumenep adalah nama salah satu kabupaten di ujung paling timur Pulau Madura, yang konon katanya merupakan Kadipaten berpangaruh atas lahirnya Kerajaan Majapahit dahulu. Berdirinya kabupaten ini tak luput dari peran tokoh zaman kerajaan yang bijaksana dan pintar yakni Arya Wiraraja (sekitar tahun 1292). Arya Wirarja sendiri merupakan salah seorang ahli strategi perang kerajaan Singasari yang memiliki banyak nama. Diantaranya, Arya Adikara. Karena sikapnya yang sering menentang kerajaan, akhirnya arya Wiraraja di pindah ke daerah Madura, menjadi Bupati Songennep. Kebijakan Raja Singasari membuat Arya Wiraraja sakit hati. Pada tahun 1292, dia melakukan gerakan pemberontakan bersama Jaya Ketawang Raja Gelang-gelang. Jaya Ketawang berhasil mengalahkan Raja Singasari Jayanegara. Akhirnya, kerjasama baik antara Arya Wiraraja dengan Jaya Ketawang terus terjalin erat. Aria Wiraraja melanjutkan upaya menbangun dan mengembangkan daerah kekuasaannya, Songennep.

Sumber lain menyebutkan, saat itu Kadipaten Sumenep berada dibawah kekuasaan Kerajaan Singosari, dengan penguasanya Raja Kertanegara. Dengan demikian Arya Wiraraja dilantik oleh Raja Kertanegara, sehingga sumber prasasti yang berhubungan dengan Raja Kertanegara dijadikan rujukan bagi penetapan Hari Jadi Kabupaten. Sumber prasasti yang dapat dijadikan sebagai rujukan adalah prasasti antara lain, Prasasti Mua

\footnotetext{
${ }^{4}$ Ibid., 234.
} 
Manurung dari Raja Wisnuwardhana berangkat tahun 1255 M, Prasasti Kranggan (Sengguruh) dari Raja Kertanegara berangkat tahun 1356 M, Prasasti Pakis Wetan dari Raja Kertanegara berangkat tahun 1267 M, Prasasti Sarwadharma dari Raja Kertanegara berangkat tahun 1269 M. Sedangkan sumber naskah (manuskrip) yang digunakan untuk menelusuri lebih lanjut tokoh Arya Wiraraja, antara lain Naskah Nagakertagama karya Rakawi Prapanca pada tahun 1365 M, Naskah Peraraton di tulis ulang tahun 1631 M, Kidung Harsa Wijaya, Kidung Ranggalawe, Kidung Pamancangan, Kidung Panji Wijayakramah, Kidung Sorandaka. Dari sumber sejarah tersebut, maka sumber sejarah Prasasti Sarwadharma yang lengkapnya berangkat tahun 31 Oktober 1269 M, merupakan sejarah yang sangat signifikan dan jelas menyebutkan bahwa saat itu Raja Kertanegara telah menjadi Raja Singosari yang berdaulat penuh dan berhak mengangkat seorang Adipati.

Prasasti Sarwadharma dari Raja Kertanegara di Desa Penampihan lereng barat Gunung Wilis Kediri. Prasasti ini tidak lagi menyebut perkataan makamanggalya atau dibawah pengawasan. Artinya saat itu Raja Kertanegara telah berkuasa penuh, dan tidak lagi dibawah pengawasan ayahandanya Raja Wisnuwardhana telah meninggal tahun 1268 M. Prasasti Sarwadharma berisi penetapan daerah menjadi daerah suatantra (berhak mengurus dirinya sendiri) dan lepas dari pengawasan wilayah thani bala (nama wilayah/daerah saat itu di Singosari). Sehingga daerah swatantra tersebut, yaitu daerah Sang Hyang Sarwadharma tidak lagi diwajibkan membayar bermacam-macam pajak, pungutan dan iuran. Atas dasar fakta sejarah ini maka pelantikan Arya Wiraraja ditetapkan tanggal 31 Oktober 1269 M, dan peristiwa itu dijadikan rujukan yang sangat kuat untuk menetapkan Hari Jadi Kabupaten Sumenep pada tanggal 31 Oktober 1269 M, yang diperingati pada setiap tahun dengan berbagai macam peristiwa seni budaya, seperti prosesi Arya Wiraraja dan rekan seni Budaya Hari Jadi Kabupaten Sumenep.

Terlepas dari perbedaan sejarah asal usul daerah, dalam sejumlah literatur, istilah Sumenep berasal dari Songennep (Bahasa Kawi). Song (lembah) dan Ennep (tenang). Songennep sendiri pada pekembangan selanjutnya diterjemahkan dengan dataran rendah dengan kondisi alam dan potensi tanahnya kaya raya. Di kawasan Songennep terdapat 
banyak pulau dan pusat energi alam. Seiring perkembangan zaman, pengucapan kata Songennep berubah. Songennep menjadi Sumenep. Perubahan pengucapan Songennep kepada Sumenep ini terjadi pada masa pemerintahan Belada, sekitar 1705 M. Politik kuasa Penjajah berhasil menaklukkan semua kawasan Madura, termasuk Sumenep. Sistem kuasi Penjajah ini berpengaruh besar terhadap peradaban masyarakat di kawasan Sumenep (dan sekitarnya). Selain merubahan pengucapan nama Songennep ke Sumenep, budaya kapitalisasi yang dijalankan Penjajah masuk ke ruang sosial masyarakat. Perekonomian masyarakat dibuat kalang kabut. Sehingga, kebutuhan besar tak sebanding dengan barang yang ada. Maklum, Belanda dengan tipologi imperalisnya, menjarah sejumlah hasil alam dan bumi untuk dibawa ke negeri mereka. Masyarakat Sumenep dengan potensi alam dan bumi yang besar tak mampu memenuhi kebutuhan sehari-hari. Masyarakat merasa tertekan di negeri sendiri. Tanah subur hanya sebatas retorika. Karena realitasnya, hasil tak pernah bisa dinikmati.

Secara geografis, kabupaten Sumenep berada diantara 113 derajat 32’54' BT-116 derajat 16'48' BT dan diantara 4 derajat 55' LS 72 derajat t24 LS, dengan batas-batas meliputi: sebelah utara bujur timur dan 455 derajat lintang selatan dengan batas daerah, meliputi sebelah utara berbatasan dengan laut Jawa, sebelah timur berbatasan dengan laut Jawa/laut Flores. Sedangkah sebelah selatan berbatasan dengan selat Madura, dan sebelah barat berbatasan dengan kabupaten pamekasan. Kabupaten Sumenep terdiri dari kawasan daratan dan kepulauan. Jumlah kecamatan sebanyak 17 kecamatan dengan 114 desa. Potensi kepulauan kabupaten Sumenep selama ini menjadi target sejumlah wisatawan manca negara. Sebab, dari 126 pulau yang ada, sejumlah pulau dianggap memiliki keunikan wahana alam. Terakhir, pulau yang menyedot perhatian publik tanah air dan mancanegera adalah pulau Gili Labek, pulau oksigen.

Kabupaten Sumenep memiliki sejumlah sektor andalan. Baik pertanian, laut, dan keseniaan. Mayoritas warga di kabupaten Sumenep berprofesi sebagai Petani. Sisanya adalah sebagai Nelayan, Pedagang, Pemborong, Pendidik, Pengusaha, dan Politisi. Produktifitas hasil pertanian di tanah Aria Wiraraja adalah Jagung. Sektor pertanian jenis jagung hampir terlihat di semua kawasan kabupaten Sumenep. Untuk kawasan daratan 
sendiri, struktur tanah pertanian memiliki perbedaan dan kelebihannya sendiri. Hal itu bisa diklasifikasi dari struktur tanah di daeah datar dan pegunungan. Jenis tanah memiliki efek terhadap hasil pertanian. Masyarakat kabupaten Sumenep menekuni pertanian sebagai sektor yang luar biasa. Pengelolaan lahan pertanian jagung lebih mudah, distribusinya sangat jelas. Meski, hasil jual terkadang tidak sebanding degan biaya proses tanam yang sudah dikeluarkan sejumlah Penduduk. Selain sektor pertanian, di kawasan pesisir, hasil laut berupa rumput laut. Rumput laut khas Sumenep terdapat di sejumlah kecamatan saja di kawasan daratan. Yakni, kecamatan Saronggi, Bluto, dan Pragaan. Selain itu, di Kecamatan Pragaan, tepatnya desa Karduluk dan Aeng panas seni ukir juga sedang menjadi lirikan banyak Pengusaha luar daerah. Sebab, hasil seni ukir Penduduk di kawasan bersangkutan dianggap memiliki nilai tawar dan nilai jual go nasional. Potensi seni ukir, dalam beberapa tahun terakhir ini menjadi bahan perhatia pemerintah daerah. Pemerintah daerah menganggap sektor seni ukir sebagai bagian upaya mengangkat citra dan prestasi kabawasan Sumenep lebih terkenal di kawasan nusantara.

Di sektor pendidikan, kabupaten Sumenep termasuk kawasan dengan puluhan pondok pesantren. Pesantren-pesantren yang ada ini memiliki jumlah santri yang banyak. Untuk konteks pulau Madura, sejumlah pondok Pesantren yang berada di kawasan Sumenep dianggap sebagai salah satu pondok pesantren dengan prestasi dan kharisma tinggi. Yaitu, pondok pesantren Annuqayah dan Pondok Pesantren Al-Amien Desa Prenduan Kecamatan Pragaan. Hasil sejumlah penelitian ilmiah, kedua pondok pesantren ini dianggap mewakili tipologi Muslim tradisionalis dan Modernis. Data empiris, tradisionalis dan modernis tersebut dilihat dari struktur dan mekanisme metodis yang dijalankan di lingkungan kedua pondok pesantren.

Kehadiran pondok pesantren di kawasan Sumenep merupakan magnet intelektualitas dan spiritualitas. Sebab, distribusi kader pondok pesantren sebagian besar mampu menjadi penyampai ajaran-ajaran kedamaian. Terbukti kehidupan beragama di kawasan Sumenep sejal masa awal hingga saat ini terjaga dengan baik. Kerukunan beragama diantara sesama warga dengan sejumlah keyakinan agama bisa berjalan dengan beriringan. Saling menjaga satu sama lain. Tentu, dalam kampium kebhinnekaan. 
Menurut data Pemerintah Sumenep, jumlah pendudk Sumenep mencapai satu juta orang lebih. Jumlah penduduk ini termasuk kategori kawasan padat. Kepadatan penduduk dalam hirarkhis sesiologis rentang dengan konflik yang bisa muncul secara tiba-tiba. Akan tetapi, ancaman konflik selama ini tidak pernah terjadi. Bahkan, kerhidupan bermasyarakat warga di semua kawasan semakin kuat. Panorama ini menjadi potret harmonis kehidupan masyarakat yang beradab. Sumenep, kawasan rendah yang tenang dan damai.

\section{Sumenep dan Gudang Metologis-Verbalis}

Sebagaimana dijelaskan di atas, kabupaten Sumenep merupakan bagian teritori kuasa propinsi Jawa Timur. Secara geografis, kawasan ini terdiri daam rimbun pedesaan. Meski wilayah dibatasi oleh perkotaan dan pedesaan, namun yang namanya pulau Madura satu rumpun, masih khas pegunungan. Sulit melihat sisi perbedaan antara orang yang berdiam di kawasan perkotaan dan pegunungan. Meski, sepintas dari sisi kebudayaan metropolitan dan papulis bisa terlihat perbedaan itu. Di kawasan kabupaten Sumenep, kepercayaan penduduk terhadap hal-hal magis (supranatural) masih kental. Sehingga, di kawasan Sumenep aura mitologis tercecar di mana-mana. Penduduk yang berdiam di kawasan pedesaan, kepercayaan terhadap hal-hal yang diluar rasionalitas begitu kuat. Salah satunya, meyakini kepada hal-hal pengahalang perjodohan yang dikenal dengan istilah sangkal. Untuk menghindari mispersepsi, sampel kajian dalam penelitian ini penulis lakukan di lima desa wilayah kabupaten Sumenep, Yaitu, desa Kadura Timur, Larangan Perreng, Karduluk, Rombasan, dan Sendang. Di lima desa ini, mitologi warga terhadap sangkal masih ada. Secara terminologis, sangkal diartikan oleh warga setempat terikat. Sulit melacak data empiris, historisitas sangkal ini. namun, data secara verbalis bisa ditemukan di semua kenangan dan cerita warga di kabupaten Sumenep. Sangkal dalam padangan orang Sumenep adalah setiap pria atau perempuan muda yang sulit mendapatkan jodoh. Penyebabnya, bisa karena menolak pinangan orang atau karena putus bertunangan. Atau bisa saja karena intervensi ilmu kotekah (ilmu hitam). ${ }^{5}$

\footnotetext{
${ }_{5}^{5}$ Disarikan dari wawancara dengan sejumlah warga sepuh di kecamatan Pragaan, Guluk-Guluk, Lenteng, dan Kapedi Sumenep.
} 
Mitologi terhadap sangkal ini berlaku secara turun temuruan di kalangan warga kabupaten Sumene Madura Jawa Timur. Meski secara ilmiah tidak bisa dibuktikan, namun rasa war-was terkadang membelenggu sejumlah kelompok di tengah-tengah masyarakat. Mengantisipasi sangkal,warga biasa melakukan ritual-ritual dengan konsep awam, sebagaimana mereka yakini. Ketika ada anak atau keluarga warga setempat yang ketiban sangkal membuang sesaji. Sesaji yang mereka buat beragam. Terkadang cukup engan daun sirih dan makanan. Ritual muang sangkal ini kemudian menginspirasi sekelompok seniman di kabupaten Sumenep menciptakan tarian muang sangkal (tarian membuang apes). Dalam konteks seniman, muang sangkal dibawakan oleh sekelompok penari lokal dengan beras kuning sebagai pelengkap tarian. Beras kuning didalam cemong (wadah tradisional) dibuang ke sekitar pengunjung. Tari muang sangkal juga bisa dibawakan saat pemerintah setempat menyambut tamu kehormatan dari luar daerah.

Sampai hasil pelacakan data ini ditulis, Penulis sulit menemukan indikatorindikator empiris yang bisa membuktikan bahwa sudah ada warga yang mendapat kutukan sangkal. Akan tetapi, secara phikologis, wacana sangkal memang membikin resah warga yang mendapat ujian sangkal. Meski tidak ada bukti nyata kutukan sagkal, namun sampai saat ini kepercayaan akan bahaya laten sangkal sulit dihilangkan di tengahtengah masyarakat kabupaten Sumenep Madura Jawa Timur.

\section{Impilikasi Medis Tahajjud; Terapi Metafisik Ala Prof. Dr. Moh. Sholeh}

Shalat tahajud merupakan ibadah sunnah yang dikerjakan pada malam hari. Sebagaimana konteks etimologis, tahajud berarti bangun tidur. Syariah mendirikan shalat tahajud sudah dilakukan oleh Nabi Muhammad Saw. Dalam sejumlah riwayat muhaddis, nabi sendiri tidak pernah meninggal shalat tahajud semasa hidupnya, sejak pertama kali ada perintah shalat tahajud. ${ }^{6}$ Bahkan, perintah mendirikan shalat tahajud bisa dilihat di sejumlah ayat al-Quran. Shalat tahajud memiliki nilai istimewa dibanding shalat shalat sunnah lainnya. Tuhan menegaskan, pada separuh malam bertahajudlah. Nisacaya, berbagai permohonan akan dikabulkan (Qs. 73:3-4). Pelaksanaan shalat tahajud dalam paktiknya, sejumlah ulama memang berbeda pendapat. Dari bilangan tiga, lima, sampai

\footnotetext{
${ }^{6}$ Moh. Sholeh, Terapi Shalat Tahajud, (Jakarta: Noura Books, 2016), 77.
} 
belasan. Perbedaan pendapat para fuqaha (ahli fikih) ini didasaran kepada dalil-dalil hadis Nabi Muhammad Saw yang mereka temukan. ${ }^{7}$ Sedangkan waktu pelaksanaan shalat tahajud pada separuh malam. Dalam konteks waktu ini, fuqaha juga berbeda pendapat. Penafsiran separuh malam dalam konteks Indonesia, antara pukul 02.00 dan 03.00 WIB. ${ }^{8}$

Terlepas dari konteks yurids fikih, bertahajud pada malam tenang merupakan kenikmatan bagi pencari kedamaian. Perintah agama (Islam) tentang shalat malam ini tentu memiliki nilai-nilai dimensional. Baik secara fisikis, phisikologis, dan aura spiritualis. Menumpahkan segala rasa pada pertengahan malam dalam irama tahajud merupakan pilihan terakhir bermunajat (komunikasi ilahiyah). Di dalam sebuah hadis yang diriwayatkan Al-Hakim dijelaskan, bahwa sedekat-dekatnya hamba kepada Tuhannya adalah pada malam terakhir. Maka, komunikasi ilahiyah yang optimal pada malam terakhir itu. ${ }^{9}$ Substansi melaksanakan tahajud memiliki efek dimensional dalam ekosistem tubuh dan prilaku Pelaksananya. Shalat tahajud dalam tinjauan medis bisa menjaga homeostasis tubuh. Yaitu, Pelaku shalat tahajud memeroleh banyak kenikmatan yang menyejukkan mata (Qs. 32: 16-17), cara berbicara yang bagus, dan berkualitas (Qs. 73:5), medapat termpat terpuji, dan terhindar dari aneka penyakit. Shalat tahajud berdasarkan hasil penelitian Prof. Dr. Moh. Sholeh bisa menghilangkan perasaan pesimis, rasa khawatir, gundah, kurang berbobot dalam cara andang, santun, dan bertanggungjawab. ${ }^{10}$ Implikasi positif tahajud ini akan membendung gaya berpikir masyarakat terhadap hal-hal yang tidak berdasar. Seperti mitologi sangkal di komunitas masyarakat kabupaten Sumenep Madura. Sebab, aktifitas shalat tahajud akan menciptakan tradisi berpikir lebih objektif, bahwa Tuhan adalah Pengendali dari semua aktifitas kehidupan ini.

\footnotetext{
7 Ibid., 116-117.

8 Ibid., 117.

9 Ibid., 118.

${ }^{10}$ Ibid., 123.
} 


\section{Catatan Akhir}

Ibadah yang diperintahkan oleh Allah Swt secara substansial memiliki energi misterius. Baik bagi situasi dan kondisi fisikis dan psikologis Pelaksananya. Misteri pelaksanaan ibadah kepada Tuhan ini akan terungkap ketika bisa dikerjakan secara optimal. Yaitu, secara ikhlas dan konsisten (istiqamah). Kedekatan hamba dengan sang Khaliq pada puncak kristalisasinya akan menciptakan suasana kedamaian total. Sebab, rahasia Tuhan esensinya hanya bisa dimaknai dengan mendekatkan diri kepada-Nya. Shalat tahajud menjadi media alternatif bagi setiap hamba untuk melakukan komunikasi spirtual dalam menjawab berbagai persoalan dalam kehidupannya. Allah Swt memiliki kendali dan kekuasaan tak terbatas. Keyakinan kepada Tuhan lewat meditasi spiritual akan menghancurkan metologi verbalis yang selama ini mengintai otak-otak minimalis (berpikir dangkal).

Pendekatan Prof. Dr. Moh. Sholeh dengan melacak sisi medis dan saintific shalat tahajud menjadi pemicu melawan mitos tak berdasar. Kekuatan Allah Swt bisa mengurai aneka penyakit (dhahir dan batin) yang ditakuti banyak orang. Semoga tawaran ilmiah dari hasil research sejumlah imuwan bisa mengembalikan marwah hamba kepada jalan yang lebih substansial. Agama dan ajaran agama bisa menjadi penggerak ke arah pedaban lebih prinsipil. Meski sangat sulit merubah mitos di masyarakat, namun selalu ada jalan ke arah yang lebih baik.

\section{Daftar Rujukan}

Athaillah, Ibnu. Al-Hikam. Jakarta: Zaman, 2015.

Al-Kahlani, Mohammad Ismael, Subulus Salâm, Jilid I. Beirut Lebanon: Dar al-Fikr, 1997.

As-Siddieqy, Muhammad Hasbi, Pedoman Shalat, Semarang: Pustaka Rizki, 1997.

Al-Anquri, Syekh Abdul Hamid, Nasihat Langit untuk Maslahat di Bumi. Jakarta: Zaman, 2015.

Arkoun, Muhammad. Rethingking Islam. USA: Westview Press Inc., 1994.

Calder, Norman. Studies in Early Muslim Jurisprudence. London: Claredon Press, 1994.

Amin, Ahmad, Islam dari Masa ke Masa. Bandung: CV. Rusyda, 1987.

Arifin, Ilmu Pendidikan Islam. Jakarta: Bumi Aksara, 2003. 
Abdullah (Ed.), Taufiq. Sejarah Umat Islam Indonesia. Jakarta: Majelis Ulama Indonesia, 1991.

Abazhah, Nizar. Sababat Muhammad. Jakarta: Zaman, 2014.

Asrohah, Hanun. Sejarah Pendidikan Islam. Ciputat: PT. Logos Wacana Ilmu, 2001.

Al-Attas, Syed Muhammad Naquib. Islam dalam Sejarah dan Kebudayaan Melayu. Bandung: Mizan, 1990.

Abdul Haq Vidyarthi \& 'Abdul Ahad Dawud. Ramalan tentang Muhammad SAW. Jakarta: Noura Books, 2013.

Abi Zakariya yahya bin Syarif an-Nawawi, Muhyiddin. al-Adzkar. Semarang: Pustaka alAalawiyah, tt.

Arikunto, Suharsimi. Pengelolaan Kelas dan Siswa. Jakarta: PT Raja Grafindo Persada, 1996.

Brockelmann, Carl. History of the Islamic Peoples. London: Roudledge \& Kegan Paul, 1982.

Damrock, David. We Scholars Changging the Culture of The University. Cambridge. Messachusetts: Harvard University Press, 1995.

Bagus, Lorens. Kamus Filsafat. Jakarta: PT Gramedia Pustaka Utama, 2002.

Basri, Hasan. Filsafat Pendidikan Islam. Bandung: Pustaka Setia, 2009.

Departemen RI. Al-Quran dan Terjemahnya. Bandung: CV J-ART, 2004.

Dimyati. Belajar dan Pembelajaran. Jakarta: Dirjen Dikti Depdikbud, 1999.

Durkheim, Emile. Ethice and The Sosiology of Morals. New York: Greenword Press, 1987.

Ghafur, Abd. Ibnu Khaldun; Pendidikan Islam dalam Konteks Manajemen Berbasis Sekolah (MBS). Surabaya: Amantra, 2011.

Hill R.B, Pathology and Disease, In Hill R.B. and La-Via M.F., Principles of Patology. New York: Oxford University Press, 1980.

Leander, Pauline. We Love Stress. Jakarta: Gramedia Pustaka Utama, 2013.

Shihab, M. Qurais. Wawasan al-Quran. Bandung: Mizan, 1996.

M. Thalib. Tuntunan Khusyuk Shalat. Bandung: Irsyad Baitus Salam, 1998.

Sholeh, Moh. Terapi Shalat Tahajud. Jakarta: Noura Books, 2016. 